PROs are important to consider as markers of future development of RA. It is necessary to expand the number of patients recruited to obtain more robust conclusions. Disclosure of Interests: Laura Nuño: None declared, Diana Peiteado: None declared, Irene Monjo: None declared, Alejandro Villalva: None declared, Marta Novella-Navarro: None declared, Maria-Eugenia Miranda-Carus Grant/research support from: BMS, Roche, Paula Fortea-Gordo Grant/research support from: BMS, Maria-Jose Santos-Bornez Grant/research support from: BMS, Eugenio de Miguel Grant/research support from: Yes (Abbvie, Novartis, Pfizer), Consultant of: Yes (Abbvie, Novartis, Pfizer), Paid instructor for: yes (AbbVie, Novartis Pfizer, MSD, BMS, UCB, Roche, Grunental, Janssen, Sanofi), Speakers bureau: yes (AbbVie, Novartis, Pfizer, MSD, BMS, UCB, Roche, Grunental, Janssen, Sanofi), Alejandro Balsa Grant/research support from: BMS, Roche, Consultant of: AbbVie, Gilead, Lilly, Pfizer, UCB, Sanofi, Sandoz, Speakers bureau: AbbVie, Lilly, Sanofi, Novartis, Pfizer, UCB, Roche, Nordic, Sandoz DOI: 10.1136/annrheumdis-2020-eular.3977

\section{AB0215 SIGNAL CAN PREDICT TO CONTINUE THE BIOLOGICAL DMARDS AFTER 1 YEAR.}

T. Okano ${ }^{1}$, K. Mamoto ${ }^{1}$, Y. Yamada ${ }^{1}$, K. Mandai ${ }^{1}$, S. Anno ${ }^{1}$, K. Inui ${ }^{1}$, T. Koike ${ }^{1}$, H. Nakamura'. 'Osaka City University Graduate School of Medicine, Osaka, Japan

Background: In rheumatoid arthritis (RA), biologics treatment is one of the effective treatment options. On the other hand, the effects of biologics cannot be obtained satisfactorily in all patients, and there are some cases in which treatment is interrupted due to ineffective or adverse events. However, the useful predictive markers of the biologics have not been found in the early phase of treatment in RA. Recently, ultrasound (US) has played a role of sensitive imaging modality in the diagnosis and follow-up of patients with RA.

Objectives: In this study, we investigated whether continuation of biologics treatment can be predicted by ultrasonographic findings in the early phase.

Methods: Fifty-four RA patients who started the first biologics from September 2016 to December 2018 were included. All the patients were performed clinical examination, blood tests and US examination of hand and foot at baseline, 4, 12, 24, 36 and 52 weeks. US examination was performed on MCP joints, PIP joints, wrist and MTP joints.

Results: Among 54 cases, 42 cases were able to continue treatment until one year later, and the continuation rate was $80.8 \%$. Of the 12 patients who discontinued first biologics treatment, 5 were changes to other biologics due to inadequate response, 4 were their wishes, and 3 were adverse events. Multiple regression analysis was performed with treatment continuation as the dependent variable and improvement of CRP, MMP-3, DAS28-CRP, grayscale score and power Doppler score in 4 weeks as explanatory variables. Only improvement of power Doppler score was extracted as a significant predictor $(p=0.045)$. In the continuation group, the improvement of the power Doppler signal at week 4 was $36 \%$ compared with the baseline, compared with $10 \%$ in the discontinuation group.

Conclusion: The early improvement of power Doppler signal in 4 weeks could be a predictive factor for the continuation of 1-year biological treatment.

References:

[1] Grassi W, Okano T, Di Geso L, Filippucci E. Imaging in rheumatoid arthritis: options, uses and optimization. Expert Rev Clin Immunol. 2015; $11: 1131-46$.

[2] Atzeni F, Talotta R, Masala IF, Bongiovanni S, Boccassini L, Sarzi-Puttini P. Biomarkers in Rheumatoid Arthritis. Isr Med Assoc J. 2017;19:512-6.

Table 1. Multivariate regression analysis of predictive factors for continuation of biologics treatment in 1-year.

\begin{tabular}{lcc}
\hline Improvement ratio of 0 to 4 weeks & beta & P value \\
\hline CRP & -0.122 & 0.465 \\
MMP-3 & 0.228 & 0.103 \\
DAS28 CRP & 0.280 & 0.103 \\
Ultrasound grey scale score & -0.342 & 0.119 \\
Ultrasound power Doppler score & 0.442 & 0.045 \\
\hline
\end{tabular}

Acknowledgments: We thank Emi Yamashita, Yuko Yoshida, Asami Fujii and Shingo Washida who performed ultrasound examination.

Disclosure of Interests: Tadashi Okano Grant/research support from: AbbVie, Eisai, Mitsubishi Tanabe Pharma Corporation and Nipponkayaku, Speakers bureau: AbbVie, Asahikasei, Astellas Pharma Inc, Ayumi Pharmaceutical, Bristol-Myers Squibb, Chugai Pharmaceutical, Daiich Sankyo, Eisai, Janssen, Lilly, Mitsubishi Tanabe Pharma Corporation, Novartis Pharma, Ono Pharmaceutical, Pfizer, Sanofi, Takeda Pharmaceutical, Teijin Pharma and UCB, Kenji Mamoto: None declared, Yutaro Yamada: None declared, Koji Mandai: None declared, Shohei Anno: None declared, Kentaro Inui Grant/research support from: Janssen Pharmaceutical K.K., Astellas Pharma

Inc., Sanofi K.K., Abbvie GK, Takeda Pharmaceutical Co. Ltd., QOL RD Co. Ltd., Mitsubishi Tanabe Pharma, Ono Pharmaceutical Co. Ltd., Eisai Co.,Ltd.,, Speakers bureau: Daiichi Sankyo Co. Ltd., Mitsubishi Tanabe Pharma, Janssen Pharmaceutica K.K., Astellas Pharma Inc., Takeda Pharmaceutical Co. Ltd., Ono Pharmaceutical Co. Ltd., Abbvie GK, Pfizer Inc., Eisai Co.,Ltd., Chugai Pharmaceutical Co., Ltd., Tatsuya Koike Grant/research support from: AbbVie, Astellas Pharma Inc, Bristol-Myers Squibb, Chugai Pharmaceutical, Eisai, Janssen, Lilly, Mitsubishi Tanabe Pharma Corporation, MSD, Ono Pharmaceutical, Pfizer, Roche, Takeda Pharmaceutical, Teijin Pharma, and UCB, Speakers bureau: AbbVie, Astellas Pharma Inc, Bristol-Myers Squibb, Chugai Pharmaceutical, Eisai, Janssen, Lilly, Mitsubishi Tanabe Pharma Corporation, MSD, Ono Pharmaceutical, Pfizer, Roche, Takeda Pharmaceutical, Teijin Pharma, and UCB, Hiroaki Nakamura Grant/research support from: Astellas Pharma Inc. and Asahi Kasei Pharma Co.

DOI: 10.1136/annrheumdis-2020-eular.2794

\section{AB0216}

(1)

POWER DOPPLER SCORE IS USEFUL TO PREDICT JOINT DESTRUCTION OF HAND AND WRIST JOINT IN RHEUMATOID ARTHRITIS PATIENTS.

S. Okita ${ }^{1,2}$, R. Nakahara ${ }^{2}$, M. Matsuhashi ${ }^{2}$, M. Watanabe ${ }^{2}$, Y. Nasu ${ }^{2}$, K. Nishida ${ }^{2}$, T. Ozaki ${ }^{2} .{ }^{1}$ Okayama City Hospital, Orthopedic Surgery, Okayama, Japan; ${ }^{2}$ Okayama University Graduate School of Medicine, Dentistry, and Pharmaceutical Sciences, Orthopedic Surgery, Okayama, Japan

Background: Several studies demonstrated that total power Doppler (PD) signal can predict radiographic progression as a change in total van der Heijde-modified total Sharp score (mTSS) in rheumatoid arthritis (RA) patients. However, in some studies, radiographic progression was observed in a different joint compared with the site of a positive PD signal at baseline in many cases.

Objectives: The aim of this study was to identify the clinical factor of RA patients in association with radiographic progression of hands and wrists and to investigate which joint showed radiographic progression in RA patients. We focused on the correlation of the site of a positive PD signal and the site of radiographic progression. Methods: We examined retrospectively of 70 RA patients (67 women, three men) who underwent ultrasonography (US) examination at 32 regions on bilateral hands and wrists from 2014 to 2016. Radiographs of the hands were taken at baseline and at least one year after US (mean, 19.9 months), and radiographic progression was assessed using mTSS system. We performed multivariate logistic regression analysis to investigate the association between baseline factors and radiographic progression. The relationships between radiographic progression of the individual joint and total/each joint PD score were assessed by ROC analysis and Fisher's exact test.

Results: Nineteen patients (37.3\%) experienced progression of mTSS of hands and wrists. DAS28-CRP $(P=0.02)$ and total PD score $(P=0.01)$ were associated with radiographic progression, and total $\mathrm{PD}$ score was significantly associated with radiographic progression (OR $1.22 ; 95 \% \mathrm{Cl} 1.04-1.36 ; \mathrm{P}=0.006$ ) by multivariate logistic regression analysis (Table 1).

Table 1. Association between the demographic and clinical findings at baseline and radiographic progression over 12 months

\begin{tabular}{lccc}
\hline a.univariate analysis & $\begin{array}{c}\text { No radiographic } \\
\text { progression } \\
(\mathrm{n}=51)\end{array}$ & $\begin{array}{c}\text { Radiographic } \\
\text { progression } \\
(\mathrm{n}=19)\end{array}$ & P-value \\
\hline Age, years & $63.4 \pm 12.7$ & $58.1 \pm 10.6$ & 0.61 \\
Duration of RA, years & $24.4 \pm 13.6$ & $20.0 \pm 5.0$ & 0.28 \\
Usage of Bio, \% & 42.2 & 40.4 & 0.57 \\
Amount of MTX, mg/week & $4.8 \pm 3.3$ & $4.5 \pm 4.3$ & 0.77 \\
Amount of PSL, mg & $1.5 \pm 2.1$ & $1.8 \pm 2.2$ & 0.73 \\
DAS28-CRP & $2.5 \pm 0.7$ & $2.9 \pm 0.6$ & $0.02^{*}$ \\
CRP, mg/dl & $0.4 \pm 0.5$ & $0.7 \pm 0.7$ & 0.10 \\
Total PD score & $2.4 \pm 3.3$ & $6.6 \pm 6.1$ & $0.01^{*}$ \\
b.multivariate analysis & odds ratio & $95 \%$ Cl & P-value \\
DAS28-CRP & 1.63 & $0.72-3.71$ & 0.238 \\
Total PD score & 1.19 & $1.04-1.36$ & $0.010^{*}$ \\
& & &
\end{tabular}

Predictive performance of total PD score was good for radiographic progression of MCP joint (AUC-ROC 0.91) and wrist joint (AUC-ROC 0.85), although poor for PIP joint (AUC-ROC 0.57).

PD score of wrist joint, MCP joint, and PIP joint were significantly associated with radiographic progression of each joint $(P<0.01)$. The sensitivity, specificity, positive predictive value, and negative predictive value of wrist joint PD score were $100 \%$, $57.0 \%, 8.0 \%$, and $100 \%$, MCP joint PD score were $85.7 \%, 90.5 \%, 8.0 \%, 99.8 \%$, and 8.3\%, and PIP joint PD score were $30.0 \%, 97.2 \%, 13.6 \%$, and $99.0 \%$, respectively. Conclusion: Total PD score of hands and wrists was a strong predictor of radiographic progression, especially in MCP and wrist joint. Evaluation of PD signa in individual joint is a clinically useful method to predict radiographic progression of the same joint, however there are some differences in sensitivity and specificity. 